\title{
A PSICOLOGIA EXPERIMENTERENDE DE KIERKEGAARD COMO RESPOSTA À PSYCHOLOGIA EMPIRICA E À EXPERIMENTELLE PSYCHOLOGIE
}

\author{
Natalia Mendes Teixeira ${ }^{1}$ \\ Universidade do Vale do Rio dos Sinos (UNISINOS) \\ (i) https://orcid.org/0000-0002-3149-2787 \\ E-mail: natalia.nmt@gmail.com
}

\section{RESUMO:}

A pergunta sobre o objeto, o método e a natureza da Psicologia, a partir do século XVIII, recebeu três propostas: (i) a primeira, apresentada por Christian Wolff, apelava para a conciliação de uma Psychologia Rationalis com uma Psychologia Empirica baseada nas etapas da Experimentalphysik e no Princípio da Razão Suficiente; a segunda, propôs uma virada para a Fisiologia, tornando-se responsável pelo recrudescimento da Psicologia como Ciência independente da Filosofia; a terceira, fundada em uma espécie de estetização da experimentação psicológica, oferece uma abordagem existencial dos fenômenos mentais. Arguiremos que o projeto de Søren Kierkegaard (1813-1855) esboçou um método que levou a diante esta última proposta recorrendo, ao mesmo tempo, a uma versão muito própria de Psicologia Experimental e opondo-se decisivamente à virada para a Fisiologia, Kierkegaard teria situado seu projeto entre a derrocada da Psychologia Empirica de Wolff e a ascendente Experimentelle Psychologie baseada na Fisiologia.

PALAVRAS-CHAVE: Psicologia; Filosofia; Kierkegaard; Século XIX; Psicologismo.

\section{KIERKEGAARD'S PSYCHOLOGY EXPERIMENTERENDE AS A RESPONSE TO PSYCHOLOGIA EMPIRICA AND EXPERIMENTELLE PSYCHOLOGIE}

\begin{abstract}
:
The question about the object, method, and nature of Psychology in the first half of the 19th century received three proposals: the first, presented by Christian Wolff, appealed to the conciliation between the Psychologia Rationalis and the Psychologia Empirica based on the process of Experimentalphysik and in the Principle of Sufficient Reason; the second, proposed a shift towards Physiology this proposal was responsible for establishing the Psychology as an independent Science; the third offers an existential approach to mental phenomena. We argue that the project of Søren Kierkegaard (1813-1855) presents a Psychology Experimenterende as a response to Psychologia Empirica and the Experimentelle Psychologie.
\end{abstract}

KEYWORDS: Psychology; Philosophy; Kierkegaard; XIX century; Psychologism.

\footnotetext{
${ }^{1}$ Doutorando(a) em Filosofia pela Universidade do Vale do Rio dos Sinos (UNISINOS), São Leopoldo - RS, Brasil.. Bolsista CAPES/PROSUC.
}

TEIXEIRA, Natalia Mendes. A psicologia experimenterende de Kierkegaard como resposta à psychologia empirica e à experimentelle psychologie. Griot : Revista de Filosofia, Amargosa - BA, v.22 n.1, p.144-156, fevereiro, 2022. 


\section{Introdução}

A transição da Filosofia da Natureza (Naturphilosophie) para às Ciências da Natureza (Naturwissenschaft) influenciou a passagem da Psychologia Empirica oitocentista de Wolff, baseada na filosofia transcendental, para a Experimentelle Psychologie baseada na nascente Fisiologia e esboçada por Wilhelm Wundt. A proposta de Psicologia de Christian Wolff (16791754) buscava preservar a natureza subjetiva da experiência de primeira pessoa, ao mesmo tempo que buscava aderir aos requisitos científicos vigentes de objetividade, validade universal e experimentação. A Psicologia seria uma espécie de Ciência sem dissociar-se da Filosofia porque Ciência era conhecimento universal e necessário acessível dedutivamente através de proposições lógicas. A Psicologia dependeria então, assim como qualquer outra Ciência, da Filosofia para assegurar seu estatuto científico. Ao final do século XIX, contudo, os novos resultados da Biologia à Química, atrelados às fissuras dos sistemas idealistas levaram as filosofias a priori, dedutivas e fundacionistas a serem questionadas e substituídas pelo paradigma das Ciências Empíricas. Os novos resultados das Naturwissenschaft provinham de métodos que incluíam observação, hipóteses, experimentação e repetição laboratorial tornando as evidências empíricas o paradigma de cientificidade ${ }^{2}$ - e não mais o mero encadeamento de proposições lógicas e análises causais indutivas.

Este artigo situa-se neste contexto, ao estabelecer a Experimenterende Psychology, a Psicologia e o método psicológico proposto pelo filósofo dinamarquês Søren Kierkegaard (18131855), dentro processo de transição de paradigma filosófico da Psychologia Empirica de Wolff (1728) para o de paradigma científico da Experimentelle Psychologie desempenhada por Wilhelm Wundt nos laboratórios da Universidade de Leipzig (1879) que culminou na formalização da Psicologia como disciplina independente da Filosofia. Esta querela culminaria, ao final do século, no Psychologismusstreit - tanto no sentido de reducionismo epistêmico e lógico, quanto de processo histórico ${ }^{3}$.

Ao opor-se à proposta de Psicologia das Filosofias fundacionistas de um lado e, de outro, ao sorver da Filosofia à Ciência - ou seja, nem a Filosofia como Ciência, nem a redução daquela à esta incorrida pela deleção de seus objetos - Kierkegaard teria de lidar com problemas éticos, performativos e epistêmicos que a Psicologia enfrentara e, assim, também garantir a observação e a repetibilidade, sem recorrer à ascendente Fisiologia ou tentar retornar à Psicologia transcendental. Assim, a proposta da Experimenterende Psychology precisaria responder à seguinte pergunta: como evitar o desafio ético, o performativo e o epistêmico e, assim, também garantir a repetibilidade, sem recorrer à Fisiologia? O texto a seguir está dividido de modo a contextualizar e responder a esta pergunta, apresentando: (i) uma breve história filosófica da querela da Psicologia expondo seu processo de transição de disciplina da Filosofia à Ciência independente; (ii) expondo os problemas que a Psicologia passaria a enfrentar pela necessidade de regulação dos fatores de observação e repetição no experimento psicológico; e por fim, (iii) argumentar como a Experimenterende Psychology, exposta n'A Repetição: um ensaio de psicologia experimental, responderia a estes problemas de observação, repetição e empiricização dos fenômenos mentais.

\footnotetext{
2 Sobre este processo conferir Depois de Hegel (Beiser, 2017).

${ }^{3} \mathrm{O}$ psicologismo é um programa que reduz epistemologicamente a Filosofia à Psicologia, ou ontologicamente um certo conjunto de entidades ou fenômenos a entidades ou fenômenos psicológicos. Sobre isso conferir: PORTA, M. Psychologism. Routledge Encyclopedia of Philosophy, New York, 2020; KUSCH, Martin. Psychologism: a case study in the sociology of philosophical knowledge. London; New York: Routledge, 1995.
} 


\section{De disciplina da filosofia a ciência independente: a querela da psicologia}

A Filosofia já capitaneava uma longa discussão sobre os fenômenos psicológicos desde os gregos. A obra que inaugura a Psicologia como estudo que interessava propriamente à Filosofia foi De Anima de Aristóteles ${ }^{4}$. Embora este estivesse travando uma discussão sobre a Psykhéprincípio comum a tudo o que vive, i.e., todos os seres dotados de anima - já com os megáricos, os pitagóricos, Epicuro, Demócrito e Platão foi a obra de Aristóteles que se tornou referência do Renascimento até os cursos de Wolff em Marburgo nos estudos dos "fenômenos comuns à psykhé e ao corpo" [PN 436a6-8]. O problema, mas também o mérito da obra, estava em tratar igualmente da alma das plantas, dos animais e dos homens sem diferenciar, portanto, fenômenos da Biologia do terreno posteriormente circunscrito à Psicologia. Para Aristóteles, a ideia de nutrição de si mesmo inclui plantas e homens e estaria presente de todas as manifestações de vida [DA 414b34].

Apenas no século XVIII, através da proposta de Christian Wolff, a Psicologia passa a ser uma preocupação mais recorrente à investigação filosófica. Para dar conta dos fenômenos mentais e das faculdades da alma, Wolff propôs uma divisão bipartide da Psicologia inspirada na Experimentalphysik newtoniana, que era dividida metodologicamente entre Física Experimental e Física Dogmática (ou teórica), tal decomposição resultaria na Psychologia Empirica (1734) e na Psychologia Rationalis (1732)5. Esta divisão guinou o debate sobre o estatuto da Psicologia na Filosofia e na Ciência porque (i) Wolff foi o primeiro a levantar a pergunta pela possibilidade de oferecer uma Psicologia Empírica ${ }^{6}$ - mesmo que ainda não se tratasse propriamente de uma Psicologia Experimental; e (ii) usou o mesmo modelo científico para a investigação de fenômenos físicos (Physis) e mentais (Psykhé).

A tarefa da Psicologia seria fornecer as razões para as coisas que são possíveis através da alma. Não se trata de duas Psicologias, senão de dois momentos da investigação psicológica. A Psychologia Rationalis seria "aquela parte da Filosofia que se ocupa da alma" (WOLFF, 1728/2006, p. 39), enquanto a Psychologia Empirica aquela "ciência que estabelece através da experiência os princípios a partir dos quais pode ser fornecida a razão para o que ocorre na alma humana" (WOLFF, 1728/2006, p. 64)7. As experiências e observações mentais coletadas em terceira pessoa chegam aos nossos sentidos de forma imediata como dados brutos e precisariam ser conduzidas por princípios filosóficos arrojados através do método da análise causal indutiva. Assim, de um lado, os resultados da Psychologia Empirica (PE) só poderiam ser conhecidos a posteriori, a partir do exame de eventos mentais através da introspecção e da auto-observação; de outro, a Psychologia Rationalis (PR) devia fornecer, através de cadeias de silogismos e análises indutivas, as possíveis consequências lógicas dos conceitos. A PE tem uma certa vantagem sobre a PR porque mantém a mente em contato direto com os dados imediatos dos fatos e atos mentais.

\footnotetext{
${ }^{4}$ O próprio termo Psicologia, ao que tudo indica, foi cunhado por Joannes Thomas Freigius, em 1575, para referir-se ao conjunto de problemas filosóficos abordados no De Anima no Parva Naturalia por Aristóteles.

${ }^{5}$ Nossa consulta sobre Wolff se baseia principalmente na tradução e comentário de Robert J. Richards em seu Christian Wolff's Prolegomena To Empirical And Rational Psychology: Translation And Commentary (1980).

${ }^{6}$ Uma diferença entre o empírico e o experimental é que o objeto em questão seria derivável empiricamente da experiência a partir da auto-observação e da introspecção, mas não seria possível experimentá-lo em terceira pessoa. Um exemplo é o caso de Johann Gottlob Krüger, que em 1756, à época de Wolff, tentou desenvolver uma teoria experimental da alma e sugeriu experimentos em pessoas condenadas pela justiça e animais. O projeto não se desenvolveu por motivos éticos e seu método acabou se direcionado à observação de casos médicos.

7 Essas duas definições complementares correspondem à sua própria definição de Filosofia - assim como Aristóteles e mais tarde Kierkegaard, Wolff não via a possibilidade de uma autonomia da Psicologia em relação à Filosofia, o que mais tarde será questionado no Psicologismusstreit e pela própria virada para a Fisiologia. A tarefa da Filosofia leibniz-wolffinana seria dupla: $a$ busca por razões pautada no princípio de razão suficiente de que tudo o que existe ou acontece tem uma razão ou causa para tal; e ser uma ciência dos possiveis, ou seja, a Filosofia deveria também demonstrar porque alguns possiveis ocorrem e outros não, o que corresponderia à investigação de como a própria realidade ocorre.
}

TEIXEIRA, Natalia Mendes. A psicologia experimenterende de Kierkegaard como resposta à psychologia empirica e à experimentelle psychologie. Griot : Revista de Filosofia, Amargosa - BA, v.22 n.1, p.144-156, fevereiro, 2022. 
A PR procede dedutivamente para demonstrar verdades sobre a mente que foram constatadas pela PE, por isso, chega mais próximo do que a PE do ideal da Ciência - ao menos daquela Ciência apriorística - por coordenar procedimentos nos quais o antecedente fornece razões para o consequente. Por outro lado, a PR convida a erros por depender de longas cadeias de raciocínios. A Psychologia Rationalis PR ofereceria, assim, o correto encadeamento de tudo aquilo que a Psychologia Empirica poderia nos fornecer através da experimentação e da observação, indicando quais conceitos se deduzem de outros. Os resultados extraídos pela experiência precisariam ainda ser reduzidos a determinados conceitos e escrutinados através da Psychologia Rationalis. Então, de certa forma, a Psychologia Empirica não poderia nos dar sozinha o conhecimento das razões daquilo que alcançamos através da observação:

Para descobrir conceitos psicológicos, a alma deve ser capaz de extrair de si própria muitas operações. É preciso, portanto, haver experiência de muitas coisas. Pois, a partir dos eventos que transcorrem em nossa alma, nós agrupamos o que pode acontecer e os reduzimos a determinados conceitos. Aquele que deseja ter conceitos correspondentes a termos e estar certo de sua verdade deve tentar experimentar em si mesmo aquelas coisas tratadas na psicologia, ou então reduzir esses termos a outros que ele possa experimentar em si próprio (WOLFF, 1980, p. 231 - grifo e tradução nossa).

O método era a introspecção direta da mente por operações normais e passivas ou por um planejamento experimental ativo. $O$ sujeito executa em si mesmo a observação, ele é o sujeitoobservador e objeto-observado - o que vai também em grande medida fundamentar também a Psicologia Experimenterende de Kierkegaard. Contudo, se a introspecção é o meio próprio de formulação das proposições científicas sobre a alma humana (WOLFF, 1728/2006 p. 227); a Psicologia Empírica precisaria regular a observação, a experimentação, a repetição e o fator performativo da experimentação psicológica.

\section{A regulação dos fatores: observação e repetição no experimento psicológico}

De acordo com o Léxico Filosófico escrito por Johann Georg Walch em 1775 - um livro que Kierkegaard mantinha em sua biblioteca - na Psicologia e na Física setecentista, a observação lidava com um objeto já preexistente; enquanto o experimento seria o momento de criação ou de partes do objeto ou do objeto propriamente (por exemplo, conceitos, categorias, etc.). Ou seja, para que haja observação é necessário um objeto pré-existente; para que haja experimento é necessária uma certa criação de partes desse objeto. Assim, a observação e o experimento podem ser dirigidos em parte a objetos que existem para além da nossa relação com eles e em parte a objetos que representam ou dependem da nossa relação com eles e, portanto, incluem uma certa interferência de nossos esforços ou percepções (WALCH, 1775, p. 325). Nesse sentido, a observação dependeria do sujeito da experiência, ou melhor, do sujeito experimentador enquanto o experimento seria propriamente o seu procedimento. Observar e experimentar seriam partes essenciais do experimento psicológico. $O$ primeiro trata dos fatos da natureza de forma passiva sem requerer nossa intervenção nela; o segundo exige um grau de intervenção na natureza, isto é, requer uma relação de produtividade, operatividade e mensuração dos fenômenos ou objetos investigados, no caso em questão, as faculdades, movimentos e operações da alma.

O sucesso do experimento, este que requer produtividade, na Experimentalphysik dependeria especialmente de dois fatores: grau de intervenção performativa e fator de repetibilidade. Se na experiência científica, dividida em observação e experimento, a observação requer atenção do sujeito-observador, e o experimento, por sua vez, precisa ser encenado ou executado pelo próprio sujeito; então, a condução do experimento inclui um certo grau de investibilidade subjetiva, isto é,

TEIXEIRA, Natalia Mendes. A psicologia experimenterende de Kierkegaard como resposta à psychologia empirica e à experimentelle psychologie. Griot : Revista de Filosofia, Amargosa - BA, v.22 n.1, p.144-156, fevereiro, 2022. 
inclui uma intervenção performativa do próprio sujeito-observador. O desafio da Psicologia wolffiana era neutralizar a intervenção performativa como fator de contaminação do experimento como a Física experimental conseguia ao tratar dos fenômenos físicos. No entanto, evidentemente, o estatuto ontológico e epistêmico dos objetos em questão é distinto. $\mathrm{O}$ grau de investibilidade subjetiva na investigação dos fenômenos mentais é consideravelmente alto porque há uma dobra: o sujeito-observador é também parte ou o próprio objeto-observado; e então, a observação de segunda ordem, ou seja, a reflexividade do ato performativo, é constantemente contaminada. Wolff não tinha uma boa resposta para isso e esta é uma das fraturas que tornou seu projeto ainda mais suscetível aos ataques de Kant.

De acordo com o Lexicon Philosophicum de J. G. Walch (1775), o segundo fator de sucesso e robustez do experimento, além do controle da intervenção performativa, é que ele fosse passível de repetições. Conduções experimentais realizadas uma única vez não poderiam ser qualificadas como propriamente experimentos científicos porque não há uma amostragem que evidencie o resultado. O desafio para Wolff era: como o procedimento feito por um único sujeito observador, feito uma única vez, e que incluía ele próprio, poderia assegurar o fator de repetibilidade? Para que haja propriamente repetição é necessário que a ideia de intervenção performativa regulada inclua um sujeito capaz de ter um olhar puramente objetivo sobre o objeto de modo que outros observadores acessem, sob as mesmas condições, o mesmo fenômeno. Essa regulação da intervenção é o que permite ao objeto ser efetivamente repetível. $O$ sucesso do experimento estava, portanto, na dependência da boa capitalização desses dois momentos: intervenção performativa e repetição. Mas o método introspectivo de Wolff não parecia dar conta da regulação desses fatores.

Kant, N'Antropologia de um ponto de vista Pragmático (1796), escrita ainda no período précrítico, argui contra a possibilidade de uma Psicologia Empírica e levanta objeções à proposta de Wolff a partir, em grande medida, dessas fissuras. Apesar da própria Antropologia de Kant, podese dizer, ter se originado das discussões com a Psicologia wolffiana e ambas terem em comum o caráter de uma "doutrina da observação" (Kant, X: 138), Kant considerou a qualificação da autoobservação como forma de experimento científico (Kant, X, 134) bem como a apreciação da Psicologia como Ciência, que utiliza os mesmos métodos da Física, indefensável.

Os motivos eram bastante interiores ao próprio projeto kantiano. Primeiro, a Física lida com objetos que possuem continuidade no espaço, e a Psicologia, que investiga a alma humana, com objetos cuja continuidade está apenas no tempo. Não pode, assim, haver continuidade da observação espaço-temporal necessária a um experimento:

[...] com essas experiências internas não se dá o mesmo que com as externas dos objetos no espaço, nas quais os objetos aparecem uns ao lado dos outros e são retidos como permanecendo nele. $\mathrm{O}$ sentido interno vê as relações de suas determinações somente no tempo, portanto, no fluxo, onde não há continuidade da observação, o que, porém, é necessário para a experiência (Kant, X, 134).

Diferente dos objetos físicos, a alma não é uma entidade acessível bidimensionalmente no espaço, apenas no tempo ( $\mathrm{KrV}$, AA 03: 052). Segundo, a observação necessariamente alteraria e distorceria o comportamento humano, ou seja, haveria uma alteração do objeto pela observação do sujeito. Haveria uma modificação natural dos estados mentais do sujeito em estado de observação: "[o sujeito] faz exatamente o contrário do que se quer dele" (KrV, AA28: 14 37). O experimentieren deveria ser feito sem provocar mudanças de estados mentais porque prejudicariam o fator de repetição ( $\mathrm{KrV}$, AA28: 749). Ao mesmo tempo, não seria possível apreender a psique como um estado imodificado porque a alma ou o estado anímico nunca é fixo. Investigar ou capturar estados mentais já é introduzir uma modificação neles. Kant argumenta pela impossibilidade de levar um outro sujeito qua pensante a incorporar nossos próprios

TEIXEIRA, Natalia Mendes. A psicologia experimenterende de Kierkegaard como resposta à psychologia empirica e à experimentelle psychologie. Griot : Revista de Filosofia, Amargosa - BA, v.22 n.1, p.144-156, fevereiro, 2022. 
esquemas mentais e experimentais sem que condenemos o experimento ética e epistemicamente. $O$ que resultaria na impossibilidade de legar, diante dessas limitações, o status de Ciência à Psicologia. Kant então defende que uma descrição natural do pensamento e do comportamento humanos só seria possível a partir da sua Anthropologie in pragmatischer Hinsicht ${ }^{8}$.

A partir da crítica kantiana, uma proposta de Psicologia precisaria resolver e equacionar as seguintes questões: como proceder para que o experimento seja confiável? Como equipar epistemicamente o observador? Quais as condições de possibilidade de acesso ao objeto? Como garantir a repetição do procedimento? Como assegurar o controle da intervenção performativa? e como lidar com a questão ética de submeter outra pessoa a experimentos mentais? Como resolver o problema da observação de segunda ordem - isto é, a observação da própria observação? Estas perguntas, ainda que indiretamente, seriam tratadas por Kierkegaard na obra, de 1843, $A$ Repetição: um ensaio de psicologia experimental.

\section{A repetição: um ensaio de psicologia experimental?}

Muitos trabalhos de Kierkegaard evocam pressupostos psicológicos já nos seus subtítulos: O Conceito de Angústia é uma "simples reflexão psicológico-demonstrativa" (1844); a Doença para a morte, uma "exposição psicológico-crist ã" (1849)9; a Repetição é "um ensaio de Psicologia Experimental" (1843). A obra que melhor localiza Kierkegaard na discussão com a Psicologia oitocentista é esta última, a Gjentagelsen: Et Forsøg $i$ Den Experimenterende Psychology. Anteriormente à escolha do subtítulo Et Forsøg $i$ Den experimenterende Psychology, Kierkegaard considerou usar Et Forsøg $i$ Experimental-Philosophie (Pap. IV B 97, p. 251), "Um ensaio de Filosofia experimental". Em 1843, contudo, quando a obra é publicada, Kierkegaard opta pelo subtítulo Et Forsøg $i$ den experimenterende Psychology mostrando a preocupação com o enquadramento do seu projeto teórico ao que à época estava em vertente debate: a possibilidade não propriamente de uma Filosofia, mas de uma Psicologia Experimental.

O dicionário dinamarquês Fremmedordbog de palavras de origem estrangeira, na versão de 1853, traduz Experiência no uso lato por Erfaring, como no alemão Erfahrung ${ }^{10}$. Sinônimos de Experiment são: ensaio (Forsøg, al.: Versuch) e prova (Prøve). Este último aparece como uma categoria importante na última parte da obra que analisa a prova de Jó. Experimental seria Erfaringsmoessig e tem sentido de "empírico"ll. Assim, à primeira vista, a escolha da tradução lusófona de Experimenterende Psychology por "Psicologia Experimental" parece não ser exata já que também Kierkegaard abertamente se opunha aos procedimentos experimentais aplicados à alma humana. José Justos, tradutor da versão lusófona de $A$ Repetição, justifica a escolha da tradução:

A expressão Experimenterende Psychologi poderia ser traduzida por psicologia experimentante [...] Psicologia, neste contexto, tem um sentido marcadamente etimológico: designa aquela parte da indagação filosófica que lida diretamente com todo o conjunto de categorias que diz respeito à alma e às respectivas manifestações ou modos de existência [...]. Experimental se aproxima muito [mais] da interpretação da ideia de experimentalismo que se encontra na segunda metade do século XX no âmbito das artes,

\footnotetext{
${ }^{8}$ Assim como mais tarde Kierkegaard, Kant entende que uma forma genuína de lidar com esses problemas de acesso à alma é pelo apelo aos recursos literários.

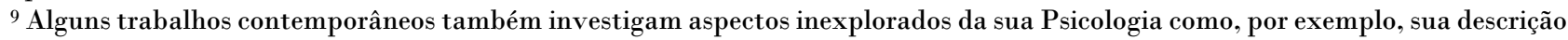
perfeitamente apropriada e antecipadora dos fenômenos psicológicos da epilepsia, àquela época pouco estudada, no Livro de Adler. Cf: The temporal lobe epilepsy syndrome elucidated through Søren Kierkegaard's authorship (H. Hansen; L. Bork Hansen, 1987).

${ }^{10} \mathrm{Em}$ Hegel, por exemplo, na Fenomenologia do Espírito é a Wissenschaft der Erfahrung des Bewusstseins (Ciência da[s] experiência[s] da consciência).

11 O dicionário Molbech de 1833 não cita Erfaringsmoessig apenas Erfaring.
}

TEIXEIRA, Natalia Mendes. A psicologia experimenterende de Kierkegaard como resposta à psychologia empirica e à experimentelle psychologie. Griot : Revista de Filosofia, Amargosa - BA, v.22 n.1, p.144-156, fevereiro, 2022. 
designadamente na poesia, nas artes plásticas e na música. Por isto mesmo faz todo o sentido manter a tradução literal da raiz lexical da palavra "experimental" em vez de optar por hipóteses de tradução muito pouco literais como imaginative constructing. ( $A$ Repetição, nota 1, p.29)

Experimenterende ${ }^{12}$ não é literalmente "experimental" porque está no particípio presente - sofrivel e sofrente, por exemplo, não carregam o mesmo sentido, embora detenham a mesma referência geral ao ato de sofrer. A tradução mais direta seria, por isso, Psicologia Experimentante ou Psicologia Experimentadora - próxima à escolha dos Hong por Experimenting Psychology. O fato é que o sentido de Experimenterende já propaga a presença e a interferência do experimentador ou observador no próprio procedimento experimental ou no ato de experiência. Por isso, a Psicologia "Experimental" de Kierkegaard é mais propriamente uma Psicologia da "experimentação", o que evoca um grau de intervenção performativa do observador. Evocar essa disputa já no subtítulo é pista suficiente - embora tenhamos muitas outras, como mostraremos - para creditarmos que Kierkegaard estava, nesta obra, em um diálogo maduro com a Psicologia do seu tempo e oferecendo uma proposta absolutamente coerente diante dos problemas que a Psicologia enfrentava àquela época.

\section{A psicologia experimenterende de Kierkegaard}

Para apresentar $A$ Repetição, Kierkegaard usa o pseudônimo com um nome bastante sugestivo: Constantino Constantius. A obra é um romance epistolar com dois personagens que trocam correspondências: o narrador e o jovem. Ela abre com um excurso denso do narrador sobre o conceito de repetição em oposição ao conceito grego de reminiscência, à anamnese socrática e ao conceito hegeliano de mediação. Cada uma das duas partes do texto parece tratar dos dois problemas do experimento psicológico: a intervenção performativa da observação psicológica, através do narrador, e a possibilidade da repetição na vida do Jovem. A obra ensaia um esquema estético-experimental. Constantino põe-se a realizar incursos psicológicos colocando as pessoas ao seu redor em enredos previamente elaborados. A narrativa do observador parte da emulação de um experimento psicológico que intenta testar a repetição como categoria psicológica. Essa categoria não aparece na natureza, mas como parte da história psicológica do indivíduo em experimento - uma entidade metafísica criada para perfazer o experimento em questão.

O narrador funciona como uma espécie de observador do experimento: "o interesse se concentra no jovem, enquanto eu sou uma pessoa em extinção" (R, p. 34). A proposta inicial do observador é, assim, desaparecer do experimento; contudo, isso não ocorre. De um lado, o narrador e suas próprias experiências também aparecem na medida em que Kierkegaard quer mostrar a importância da situação existencial do observador para o experimento. Ele nos conta suas impressões sobre a cidade e seus transeuntes e sobre sua visita ao Königsstädtisches Theater, por exemplo. De outro, ele também intervém na experiência do jovem, chega a prever sentimentos e acontecimentos que o acometeriam, a sugerir comportamentos e interferir performaticamente e de forma ativa no experimento. Ou seja, a obra parte de um movimento do narrador da condição de mero observador passivo para a de experimentador ativo, criando partes do objeto analisado,

\footnotetext{
12 Uma forma de explicar essa consideração inicial do subtítulo "Filosofia experimental" deve-se também ao impacto do sucesso da física newtoniana sobre a Filosofia no século XVIII. Embora o termo e a proposta tenham sido rejeitados pela filosofia crítica de Kant, eles foram posteriormente reincorporados por alguns românticos com propostas tais como "física experimental da mente ou do espírito": Cf. Jürgen Daiber Experimentalphysik des Geistes. Novalis und das romantische Experiment, Göttingen 2001. Schlegel também teria dito que o método da Filosofia é, antes de tudo, um experimento. Cf: Friedrich Schlegel. Philosophische Vorlesungen (1800-1807). Mas aqui trata-se do sentido de uma experiência não propriamente científica, mas artística.
}

TEIXEIRA, Natalia Mendes. A psicologia experimenterende de Kierkegaard como resposta à psychologia empirica e à experimentelle psychologie. Griot : Revista de Filosofia, Amargosa - BA, v.22 n.1, p.144-156, fevereiro, 2022. 
ensaiando colocá-lo em situações a fim de desenvolver um tipo de maturidade ou testar categorias psicológicas:

Começara a comportar-me frente a ele de modo observador; já não podia deixar de conduzir toda a espécie de experiências no intuito de, como diz o marinheiro, lançar a barquilha para avaliar a velocidade daquela melancolia $(R, p .37)$.

Outro aspecto da intervenção performativa do narrador é não apenas a interferência inevitável do observador na experiência, mas o efeito do comportamento do sujeito-observado sobre as experiências e impressões do próprio observador:

Porque o seu belo aspecto, a expressão dos olhos plena de sentimento, tinha sobre mim um efeito quase tentador [...] há muito tempo não me sentia assim [...] porque muitas vezes é bastante triste ser-se observador $(\mathrm{R}, \mathrm{p} .34 / 35)$

Com esse envolvimento, o narrador mostra a impossibilidade de se constituir como mero observador-espectador diante de experiências humanas:

Em geral todas as emoções humanas profundas desarmam no homem o observador que nele possa haver. Querer observar só acontece quando em vez de tais emoções se encontra um vazio ou quando alguma coqueteria as encobre [...] quem poderia ser inumano ao ponto de ficar a observá-lo friamente, quem não se sentiria invadido por uma emanação do fervor desse indivíduo [...] Diante de um discurso que torce e retorce palavras de forma objetiva colocamos muito calmamente o microscópio à frente dos olhos $(\mathrm{R}, \mathrm{p} .34-35)$.

Assim, Constantino está mostrando a profunda afetação que a experiência do jovem causa sobre ele próprio. Kierkegaard consegue mostrar que a neutralidade das Experimentalphisik não pode ser aplicada à relação de intersubjetividade implicada na observação de fenômenos mentais e experiências de primeira e terceira pessoa. A posição do observador no experimento, segundo Kierkegaard, ao invés de se esquivar da intervenção performativa, ele a incorpora ao experimento fortalecendo a subjetividade e a imaginação do observador no procedimento de experimentação ao invés de tentar neutralizá-la. Ainda em outras obras Kierkegaard fala sobre a condição epistêmica do observador no procedimento psicológico. No Conceito de Ironia (1841) e nos Discursos Edificantes, respectivamente, encontramos:

O observador deve ser um erótico, nenhum traço, nenhum momento pode ser indiferente para ele; $[\ldots]$ pois, se bem que o observador traga o conceito consigo, importa, mesmo assim, que o fenômeno não seja violentado, e se veja o conceito surgindo a partir do fenômeno (CI, p. 23).

Não depende apenas do que se vê [o objeto], mas o que se vê depende de como se vê [método]; toda observação não é apenas um recebimento, uma descoberta, mas também uma criação (bringing forth)[resultado], e na medida em que é assim, como o próprio observador é constituído é de fato decisivo. [Quando] o objeto visto pertence ao mundo externo, então como o observador é constituído é provavelmente menos importante ou, mais corretamente, o que é necessário para a observação é algo irrelevante para sua natureza mais profunda" (EUD, p. 59 - tradução nossa).

Nesta última citação do Eighteen Upbuilding Discourses - EUD de 1845, Kierkegaard faz uma distinção entre um observador de um objeto externo, pertencente ao mundo e outro de um objeto pertencente ao mundo psíquico. Neste caso, deveria ser levado em consideração a constituição interna do próprio observador; quando, ao contrário, trata-se de objetos do mundo externo (isto é, físicos), a natureza mais profunda do observador é irrelevante. No primeiro caso,

TEIXEIRA, Natalia Mendes. A psicologia experimenterende de Kierkegaard como resposta à psychologia empirica e à experimentelle psychologie. Griot : Revista de Filosofia, Amargosa - BA, v.22 n.1, p.144-156, fevereiro, 2022. 
o objeto é uma criação, um resultado cujas variáveis dependem não apenas do objeto cognoscível, mas do método e do observador - a diferença está na relação do objeto com o próprio observador. Além da equação epistêmica formada entre a tipologia, a ontologia do objeto (o que se vê) e a metodologia da observação (como se vê), Kierkegaard tece uma crítica à neutralidade inquestionável das ciências sem distinção e rigor. $O$ cientista não está fora da história, mas situado dentro de um nexo histórico e cultural que pode modelar suas observações; i.e., nenhuma descoberta é a-histórica ou atemporal e, por isso mesmo é, em alguma medida, uma criação, isto é, resultado de fatores diversos. A situação do observador, do pensador objetivo determina, em certo sentido, o que ele vê; ainda que sua constituição interna não. Fatos inteiramente neutros seriam, portanto, quiméricos; toda observação seria uma espécie de criação equacionada entre o observador, objeto e as variáveis externas.

N'A Repetição, o experimento psicológico aparece como uma espécie de performance teatral - um exemplo é quando o narrador diz que pretendia seguir o jovem para obter mais informações e propõe juntamente com ele emular uma situação. Chenxi Tang defende que o aspecto farsesco e acidental parece se opor à idealidade artística nessa obra, a farsa é caracterizada por uma certa teatralidade do acidental: "o espectador é comicamente reconciliado ao assistir essa concreção acidental fazer uma reinvindicação para ser ideal, o que ela faz pisando no mundo artificial do palco" (R, p.164). O observador, Constantino, torna-se espectador de uma farsa que ele criou. A realidade parece ser interessante apenas porque o acidental ou contingente recebe maior significado ao repousar sobre seu olhar teatral. Mas que resultados robustos uma experimentação psicológica teatralizada poderia oferecer? Nenhuma. Para Kierkegaard, em certo aspecto, o que a Ciência experimental realizava era uma espécie de teatralização dos fenômenos da vida. $O$ cientista ensaiava uma espécie de farsa - é possível que Kierkegaard quisesse também apresentar uma certa irresponsabilidade ética nesse tipo de procedimento ensaístico ou ainda, argumentar que o aspecto acidental da performatividade tornaria o experimento algo impossível de ser repetido e ter confiabilidade.

No entanto, da primeira à segunda parte, para resolver o problema da interferência subjetiva, ele muda seu foco da subjetividade do observador para a situação existencial do observado. O objeto de experimentação continua sendo o jovem, mas há uma inversão de perspectivas: das notas do observador à auto-observação do observado. Se a primeira parte é narrada pela voz de um espectador do teatro em busca da repetição na vida do sujeito observado, emulando aspectos farsescos; a segunda, é construída pelo único que poderia de fato experimentála: o sujeito da observação.

$\mathrm{O}$ método de Kierkegaard consistira em dois elementos centrais: primeiro, a posição do observador deve ser de uma preocupação apaixonada com a sua própria situação existencial o que torna irrelevante qualquer interesse puramente cognitivo ou técnico em adquirir conhecimento psicológico sobre os outros; e, segundo a própria subjetividade do observador é incorporada no processo. $O$ experimento é, ainda, uma espécie de prova psicológica e existencial (Prøvelse) com duração não prevista e resultado incerto. Por isso, na segunda parte, o caso de Jó é trazido para mostrar que, quando o indivíduo vive uma experiência psicológica, uma provação, os demais só podem participar na condição de observadores: os amigos de Jó falam de sofrimento, mas é Jó quem o vivencia. Mesmo que a avaliação desses observadores esteja correta, elas permanecem apenas como um tipo de juízo externo à própria situação existencial de quem vive a experiência; e, portanto, da própria realidade do experimento.

Os amigos de Jó funcionam aqui como um exemplo da própria falibilidade da observação e da erudição da Ciência sobre os fenômenos, eventos e experiências psicológicas de terceira pessoa, é por isso que uma Psicologia Experimental não é possível, apenas uma Psicologia da Experiência cujo observador e experimentador é, no melhor cenário, o próprio indivíduo - em certo sentido,

TEIXEIRA, Natalia Mendes. A psicologia experimenterende de Kierkegaard como resposta à psychologia empirica e à experimentelle psychologie. Griot : Revista de Filosofia, Amargosa - BA, v.22 n.1, p.144-156, fevereiro, 2022. 
Kierkegaard está na mesma via da introspecção wolffiana. A repetição em experimentos e objetos que não se alteram diante da observação pode ser garantida pelas ciências empíricas; Kierkegaard conseguiu mostrar que na vida do individuo a única repetição possível é aquela que é vista subjetivamente, aquela em que o sujeito se dobra sobre ele próprio: ele é o sujeito-objeto da observação e da experimentação.

Chenxi Tang (2002) também defende que esse texto de Kierkegaard ensaia a crise da experimentação psicológica no século XIX e sua Psicologia é uma proposta de solução a ela:

Constantino vislumbra uma alternativa poderosa ao método quantitativo fisiológico. Essa concepção alternativa de experimentação psicológica prevista na segunda parte do texto implica uma noção de tempo e repetição distinta daquela da era técnica que se avultava em meados do século XIX. [...] Em suma, parece que a narrativa da jornada espiritual do jovem se presta a pelo menos dois tipos de leitura. Podemos lê-lo como um experimento conduzido com o propósito de ilustrar a categoria psicológica da repetição, ou podemos considerá-lo como uma encenação da crise da psicologia experimental e subsequentemente apontando para uma saída dessa crise. Esses dois tipos de leitura, no entanto, acabarão por convergir (TANG, 2002, p.107 - grifo e tradução nossa).

E ainda:

\begin{abstract}
Particularmente na esteira da transição do método qualitativo para o quantitativo, por volta de 1840, experimentos fisiológicos cada vez mais recorreram a dispositivos técnicos para facilitar a observação, preparar órgãos para a observação, induzir, supervisionar e controlar mudanças artificiais nos órgãos sensoriais e em outros e, finalmente, medir e calcular resultados. $\mathrm{O}$ ser humano foi, assim, cada vez mais intimamente e mais profundamente ligado ao aparato técnico e, portanto, moldado como parte de um sistema técnico mais amplo. Por exemplo, em conexão com os experimentos relacionados à visão em andamento, os dispositivos visuais proliferaram no século XIX (TANG, 2002 - grifo e tradução nossa).
\end{abstract}

O projeto que Kierkegaard vai defender no contexto de transição da Psicologia Empírica wolffiana como paradigma institucional para a institucionalização da Psicologia Experimental oitocentista é assim que, se de um lado é possível usar conceitos metafísicos para propor uma ontologia ou, como prefere a tradição intérprete, uma fenomenologia dos acontecimentos mentais; de outro, é pela experiência, mais propriamente através da introspecção e da observação, que acessamos os fenômenos psicológicos que descrevemos. No entanto, o tipo de experiência que torna os fenômenos psicológicos acessíveis ao sujeito-observador não é o mesmo tipo de experiência que torna objetos físicos acessíveis aos cientistas. Essa tese de Kierkegaard é tão impressionantemente madura para seu tempo quando é enormemente negligenciada pela história da Filosofia e da Psicologia e pela própria tradição intérprete especializada. Apesar de Kant ter identificado o problema primeiro; Kierkegaard tem uma proposta arrojada para lidar com ele e a persegue linearmente em todo o seu projeto.

Algumas das respostas de Kierkegaard às perguntas que acima formulamos, são: (i) a situação existencial do observador conta no procedimento da psicologia experimental; (ii) os resultados da experimenterende só são completos quando o sujeito qua existente é o próprio observador ou, na melhor das hipóteses, é existencialmente interessado no próprio sujeito que passa pela experiência; (iii) o observador-experimentador só extrai aspectos ensaísticos e farsescos da realidade; a questão é como o observador pode extrair conhecimento confiável sobre uma experiência de terceira pessoa; (iv) a intervenção performativa precisa ser equacionada no experimento, ela é inevitável; (v) a repetição só é possível como Prøvelse (prova, teste, ensaio) submetida ao próprio sujeito experimentante; (vi) se o observador for moralmente impecável,

TEIXEIRA, Natalia Mendes. A psicologia experimenterende de Kierkegaard como resposta à psychologia empirica e à experimentelle psychologie. Griot : Revista de Filosofia, Amargosa - BA, v.22 n.1, p.144-156, fevereiro, 2022. 
haverá alteração de comportamento por parte do sujeito observado (R, p. 88); (vii) há uma relação recíproca entre observador e observado: há um aspecto intersubjetivo na construção do objeto e do experimento porque o observador compromete-se com fervor com o observado ( $R, p .67)$; (viii) no processo, o observador também se experimenta e se modifica; (ix) o observador não consegue repetir o mesmo experimento em terceira pessoa.

\section{Conclusão}

Wolff buscou introduzir os procedimentos da Experimentalphysik-experimento, observação e repetição. Ao contrário da Experimentelle Psychologie, a Psicologia Empírica wolffiana encontraria atravanques metodológicos e epistêmicos para assegurar a observação, a experimentação e o fator de repetibilidade dos fenômenos ou objetos mentais, o motivo: o aspecto performativo surgiria como um interstício ético e epistêmico. Apenas a Psicologia experimental e fisiológica do final do século, ao recorrer ao método quantitativo-experimental e abandonar o qualitativo-empírico, teria recursos epistêmicos e expediente metodológico para litigiar estes problemas - e Kierkegaard teria que lidar com eles se quisesse oferecer uma alternativa à Fisiologia.

Kant não foi, assim, o único a condenar a tentativa de falar da alma humana a partir de uma Experimentalphysik por serem os procedimentos da Física impossíveis de se aplicar à mente ou à alma humana; Kierkegaard também se opôs à Psicologia como Wissenschaft e ofereceu sua alternativa: a substituição da observação experimental e objetiva pela observação experimentadora (Experimenterende). Ao contrário de Kant, Kierkegaard defenderá a autoobservação como fonte inesgotável de recursos psicológicos; e que, sendo o observador bem treinado para os fenômenos, a suposta mudança de comportamento diante da observação não compromete o experimento e pode ser incorporada a ele. Kierkegaard estava ciente da impossibilidade de regulação tanto da intervenção performativa quanto da possibilidade de repetição em experimentos mentais, ou melhor, experimentações psicológicas e, segundo ele: i) há um investimento subjetivo por parte do observador que faz o experimento; ii) o ser humano não é ontologicamente idêntico aos objetos físicos; iii) fazer experimentos em seres humanos acarreta questões éticas que não estão implicadas nos experimentos físicos; iv) o investimento subjetivo na observação é inevitavelmente incorporado à própria observação; e, portanto, v) as experiências psicológicas do observador-experimentador não são, de nenhuma forma, repetíveis. 


\section{Referências}

ARAUJO, Saulo De Freitas, "O Lugar de Christian Wolff na História da Psicologia". Universitas Psychologica, 3, 11 p. 1024, 2012.

ARISTÓTELES. De Anima. Tradução: Maria Cecília Gomes dos Reis. Editora 34, 2012. ARISTÓTELES. Parva Naturalia. Oxford: New York: Oxford at the Clarendon Press, 2000. BEISER, Frederick. Depois de Hegel. Editora Unisinos: São Leopoldo, 2017.

BELL, Mathew. The German Tradition of Psychology in Literature and Thought, 1700-1840. Cambridge: University Press, 2005.

BRENTANO, Franz. O Psicologismo: Ou o porquê não sou um psicologista. Trad: Evandro Brito. Revista Peri, V 05. N 01, p. 169-172, 2013.

DAIBER, Jürgen, Experimentalphysik des Geistes: Novalis und das romantische Experiment. Vandenhoeck \& Ruprecht, Göttingen, p.330, 2001.

DYCK, Corey. Kant and rational psychology. Oxford University Press, Oxford, United Kingdom ; New York, NY, First edition., p.257, 2014.

HANSEN, H. y HANSEN, L. Bork, "The temporal lobe epilepsy syndrome elucidated through Søren Kierkegaard's authorship and life". Acta Psychiatrica Scandinavica, 3, 77, p. 352-358, 1988.

HATFIELD, Gary, "Kant and Empirical Psychology in the 18Th Century". Psychological Science, 6, 9. p. 423-428, 1998.

HEGEL, G. W. F. Fenomenologia do espírito. 1. Ed. Vozes, Petrópolis, 6. ed., p. 271, 2001.

KANT, I. Anthropologie in pragmatischer Hinsicht. Reinhard Brandt. Meiner: Hamburg, 2000.

KANT, I. Crítica Da Razão Pura. Lisboa: Fundação Calouste Gulbenkian, 2001.

KIERKEGAARD, S. Eighteen upbuilding discourses. Princeton University Press, Princeton, N.J, p. 559, 1990.

KIERKEGAARD, S. A Repetição: Um ensaio em psicologia experimental. Tradução de José Miranda Justo. Lisboa: Relógio d'água, 2008.

KIERKEGAARD, S. A. Fear and Trembling; Repetition, tradução de Howard V. Hong e Edna H. Hong. Princeton, New Jersey: Princeton University Press, 1983.

KIERKEGAARD, S. Pós-escrito às migalhas filosóficas. Tradução de Álvaro Montenegro Valls. São Paulo: Vozes, 2013.

KIERKEGAARD, Søren. O conceito de ironia: constantemente referido a Sócrates. Tradução de Álvaro Valls. Ed. Universitária São Francisco, Bragança Paulista, 2006.

KLEMPE, Sven Hroar, "Kierkegaard and Psychology as the Science of the "Multifarious Life"". Integrative Psychological and Behavioral Science, 3, 47, p. 367-375, 2013.

KRÜGER. Versuch einer Experimental-Seelenlehre. Halle/Helmst dt: Hemmerde, 1756.

KURZER, J. G. S. Begriff aller Wissenschaften und ändern Teilen der Gelehrsamkeit. Frankfurt, Leipzig, p. 130, 1786.

KUSCH, Martin. Psychologism: a case study in the sociology of philosophical knowledge. London; New York: Routledge, 1995.

MCCARTHY, Vincent A., Kierkegaard as psychologist. Northwestern University Press, Evanston, Illinois, 2015, p.190, 2015.

MCDONALD, W. Kierkegaard's experimenting Psychology. In: Buben, Adam (ed.), The Kierkegaardian mind. Routledge, New York, 2019.

MOLBECH, C. Dansk Ordbog indeholdende det danske Sprogs Stammeord, Copenhagen: Gyldendal, 2 vols, 1833.

Ordbog over det danske Sprog - Historisk Ordbog - 1700-1950, 2014. 28 vols. Disponível em http://ordnet.dk/ods. Último acesso em: 22 de fevereiro de 2022.

TEIXEIRA, Natalia Mendes. A psicologia experimenterende de Kierkegaard como resposta à psychologia empirica e à experimentelle psychologie. Griot : Revista de Filosofia, Amargosa - BA, v.22 n.1, p.144-156, fevereiro, 2022. 
PORTA, M. Psychologism. Routledge encyclopedia of philosophy. Routledge, London; New York, 2020.

SCHLEGEL, Friedrich von. Philosophische Vorlesungen [1800-1807]: zweiter teil. Schöningh, München, 1964.

SHARPLESS, Brian A., "Kierkegaard's conception of psychology." Journal of Theoretical and Philosophical Psychology, 2, 33, p. 90-106, 2013.

SUZUKI, Márcio, "Os desdobramentos da psicologia experimental em Moritz, Kant e Kierkegaard". DoisPontos, 1, 17, 2020.

TANG, Chenxi. Kierkegaard and the Culture of Psychological Experimentation in the Nineteenth Century. KulturPoetik, Bd. 6, H. 2 p. 172-188 2006.

TANG, Chenxi. Repetition and Nineteenth-Century Experimental Psychology. Kierkegaard Studies Yearbook, 2002.

WALCH, J. G. Philosophisches Lexicon, Ed Justus Christian Hennings, Ed. 4. Leipzig, p. 324-5, 1775 .

WOLFF, C. Einleitende Abhandlung uber Philosophie im allgemeinen (G. Gawlick und L. Kreimendahl, Übers. und Hgg.). Stuttgart/Bad Cannstatt: Frommann- Holzboog. Erstausgabe, $1728 / 2006$.

WOLFF, C. Philosophia rationalis sive Logica. Frankfurt: Rengeriana, 1732.

WOLFF, C. Prolegomena to empirical and rational psychology. In: R. Richards. Christian Wolff's prolegomena to empirical and rational psychology: Translation and commentary. Proceedings of the American Philosophical Society, p. 227-239, 1980.

WOLFF, C. Psychologia empirica, methodo scientifica pertractata. Frankfurt/Leipzig: Rengeriana, 1738.

WUNDT, W. Outlines of Psychology. Leipzig: W. Engleman, 1897.

WUNDT, W. Principles of physiological psychology. Trans: E. B. Titchener. Sonnenschein: London, 1904.

Autor(a) para correspondência / Corresponding author: Natalia Mendes Teixeira. natalia.nmt@gmail.com 